\title{
The Influence of Ming Dynasty Martial Art on the Development of Today's Society
}

\author{
Shangwu Tao \\ College of Physical Education, Yan'an University, Yan'an 716000, China \\ 236488990@qq.com
}

\begin{abstract}
Martial art is one of Chinese traditional events, it is a treasure of the Chinese civilization in the glorious and resplendent. In its long evolution, Ming Dynasty has epoch-making significance .This period is the heyday of the development of Chinese martial arts, The boxing number is unprecedented in the history. To provide reference for the development of martial arts in China today by expounding and comparing the characteristics of Ming Dynasty and contemporary society and the development of martial arts.
\end{abstract}

Keywords: The Ming Dynasty, A martial art, Development.

\section{Introduction}

Martial arts is a treasure of our traditional culture of the Chinese nation, with distinctive cultural and ethnic characteristics. In its long process of development, the Ming Dynasty has the epoch-making significance: Ming Dynasty martial arts not only summarize the crystallization of the ancient sages, but also in the hyality of innovation, there have been many new boxing [1]. When entering the 21st century, with the development of the times, the concept of fitness care has been deeply rooted. As the Chinese martial arts not only has a wonderful and offensive and defensive skills, but also has a health-style sports with the fun, which makes our traditional martial arts movement showing an ascendant situation. However, with the deepening of globalization, Western foreign sports are also popular with people, especially young people welcome, which makes martial arts in the efforts of internal innovation at the same time, facing the challenge of external Western competitive projects. This article elaborates and compares the respective characteristics of the Ming Dynasty and the present society. As well as the development of the Ming Dynasty martial arts, to explore the future development of our martial arts today.

\section{Ming Dynasty unique social characteristics}

\subsection{Prosperous economy and growing autocratic society}

The economy of the Ming Dynasty in the history of China is a more developed stage, with the gradual stabilization of society in the early Ming Dynasty, agriculture, handicraft industry can be quickly restored and developed. The city began to expand the scale, the rapid growth of the public class, which makes the Ming Dynasty people's basic necessities, festivals and cultural beliefs, cultural life and so are showing a rich situation. In the political system, the Ming emperor Zhu Yuan-zhang abolished the prime minister system, and later established the Jin Yiwei, East factory and the West plant, forming a strict spy supervision, the regime basically concentrated to the hands of the emperor. And the emperor's faint and this led to the late Ming dynasty eunuch chaos.

In the Ming dynasty of China, the West began the Renaissance, the Reformation Movement and the new route to open up, the Western countries began to seize the colonies in the world, plundered resources. The status of the western countries in the world gradually more than the East, the status of China's world power is facing increasingly serious challenges. In addition, With the isolated areas of the world began to contact, Western also with a group of missionaries came to China, for the exchange of things opened up a window of culture, but also affect the development of oriental culture. 


\subsection{The culture of the Ming dynasty gradually solidified}

Although the Han Emperor proposed "exclusive Confucianism", But the Chinese culture has been in the Buddha, Tao, Confucianism mixed with the state. Ming dynasty set up captive, regular trial, the provisions of Confucianism, especially Cheng Zhu Neo-Confucianism for orthodox thought. This is actually a cultural dictatorship. It binds the minds of intellectuals to Confucius and Mencius. Readers for the hunting fame, buried in the "four books five", write empty eight shares, all useful knowledge, do not care. Not only to a group of social elite reduced to the imperial power of the vassal, but also detained people's thinking, a serious impediment to the development of cultural science.

\subsection{Ming Dynasty "tribute" diplomacy}

The early Ming Dynasty in order to prevent the pirates harassment in coastal areas, the emperor issued a ban on the sea ban policy, cut off since the Tang and Song dynasties since the increasingly prosperous folk maritime trade. Since then, if you want to come to China to do business, must tribute and trade, or not, this is the so-called "tribute trade" [2]. But this kind of diplomacy with obvious oriental imperial power, just used to highlight the imperial dignity, to achieve official monopoly business overseas trade, but also with Huairou to draw around the country's use, the development of civil free trade only play a hindrance.

\section{The Development of martial art in Ming Dynasty}

Due to the stability of society, the Ming Dynasty martial arts have been unprecedented development. However, the side has not been eradicated, whether it is the north of Mongolia, southeast of the pirates or northeast of Manchuria Jurchen, the Ming regime there is a threat. Therefore, the training of the Ming Dynasty army, always military practical as the standard, pay attention to each action of the offensive and defensive meaning and the actual effect. In the military training of soldiers, tried to exclude some of the only good-looking without the meaning of the enemy's flower shelves, so that the military martial arts toward the "enemy wins", pragmatic focus on the direction of development. At the same time, people have recognized that martial arts has a fitness function. From the perspective of fitness, performance effects, some in the battle did not use the "flower method", and looks very small and moving "around the deal, full of flowers," the "virtual set" is loved by the masses. Especially with the development of the city and the growth of the public class, the urgent need to belong to their own culture. So, this kind of martial arts gradually separated from the military operations, According to their own development law forward, gradually "civilians", slowly evolved into sports.

\subsection{Wushu routines and Countermeasures}

Frequent military campaigns, Aggressive combat Technology and routine technology in the Ming Dynasty has been unprecedented development, and formed a number of technical schools. In the Ming Dynasty, the basic movement of Wushu routine. Different from the past, Routine movement is no longer just a simple accumulation of offensive and defensive combat action, There is a "start" and "closed", There will be a variety of defensive action completely connected "about the deal "of cohesion action, There are some interesting tricks. These are marked by the further development and improvement of routine movement. For example, "Flower law" routine practice, Pay attention to hand, leg, body method and step, to achieve a very high level of skill.

\subsection{The formation of martial arts system}

Ming Dynasty martial arts technology genre a lot, Such as boxing Qi Jiguang "thirty-two potential", Chen Wang Ting's "Tai Chi" and so on; Gun in the "Yang gun", "horse gun", "Shaolin gun" and so on. As a result of various new schools everywhere, there is a "home" and "home" points. Inside the box to pay attention to static brake, to air capacity, to static brake, to soft grams just to air capacity, etc., And "outside the boxing" is hard to play hard, rigid and rugged. In addition, the Ming Dynasty there are many martial arts monographs come out. These martial arts monographs, to promote the formation of the schools and learn from each other to absorb, and thus promote the development of various 
technologies played a significant role. More well-known Tang Shun of the "martial arts", Qi Jiguang's "Documentary New Book" and so on. These books in the description of routines, offensive and defensive methods and actions, are recorded with the map of the trick moves and routes and so on. This is a pioneering work, thus changing the previous martial arts can only teach the history alone. This kind of improved martial arts works once again speed up the overall development speed of the Ming Dynasty martial arts.

\subsection{Martial arts weapons and theory}

Sabreplay get faster development than other cold weapons in the Ming Dynasty, there is a very important factor in history. In the Japanese invasion, Many military generals found: Short sword even worse than the Chinese sword, So our army famous anti-Japanese star Qi Jiguang in the long campaign, According to China's traditional sabreplay, absorb the advantages of the short sword, To study the famous "Xin You knife law", The Chinese sabreplay has greatly enriched. The Ming Dynasty cudgel play also has great development, Stick is regarded as a martial artist, since ancient time's popular attention, competing development, the formation of many martial art. Ming popular popular sticks have "Shaolin stick", "Qingtian stick", "Pakistan children stick", "cattle home stick" and so on. Among them, Shaolin sticks in addition to sticks thick, in the stick on the highlight of the big split action. In the real pirates in combat, Shaolin sticks in dealing with the lighter of the short sword played a very important role, Shaolin monks in the Ming Dynasty anti-Japanese war also repeated legislation exploits, writing a legend. The Ming Dynasty cudgel play theory also has development, Such as Qi Jiguang's "short soldiers", Yu Dayou taught the Shaolin monk's sword (stick) by ("sword by" is Yu Dayou teach the stick method of specialized works) and so on. These theories have had a positive effect on the development of later swords. On the basis of the development of the Song Dynasty, the Ming Dynasty gunmen martial art of the famous Young's "pear gun", as well as "sand house gun", "inside the gun", "Shi gun", "Ma gun", "Lee spear", "Zhang Fei guns", "Liuhe gun" and so on. Ming Dynasty gun technology in the technical development of another "long soldiers can be short". This feature provides a new way for your footwork, body, marksmanship and tactical development.

\section{The development trend of today's martial arts}

\subsection{Martial arts to diversify the development}

The martial arts culture has a long history, the source is distant and the stream long, with distinctive national characteristics, but also the majority of people love one of the ways of physical fitness. After the founding of new China, the government focused on the development of martial arts ornamental, performing side, while the evolution of many new routines. With the development of the economy, Modern martial arts has opened up a new road, The combination of martial arts and tourism to open up tourist routes, Coach in the accompanying martial arts, So that visitors in the lush mountains of the pleasant atmosphere, Enjoy the charm of martial arts, Experience the traditional culture of martial arts, So that tourism and martial arts to win.

\subsection{Martial arts to the scientific development}

Martial arts in the long historical process, Continue to absorb and integrate the traditional Chinese medicine, Guided surgery and other theories and methods, So that its unique physical fitness with other projects can not be superior to the advantages of [3]. From the health point of view, Chinese martial arts is based on the guidance of Chinese medicine theory, It has the so-called "fist began in easy to manage" in the argument. In the theory of meridians and Qigong with the same pulse theory of traditional Chinese medicine, which makes martial arts, sports and medicine, they can mastery. These martial arts concept is the accumulation of thousands of years of history and culture, martial arts practitioners on their own experience of simple summary, there are certain limitations. With the continuous development of modern human science, the human body structure, life activities to understand the increase in the concept of martial arts is also toward the direction of scientific development. 


\subsection{The Development of martial arts to Internationalization}

Chinese martial arts through thousands of years, it has been rooted in the Chinese traditional culture in china. In the process of its development, it combines the Chinese of traditional philosophy, ethics, medicine, military science, aesthetics, health science and traditional cultural ideas and concepts. Along with the gradual progress of China to the world, the globalization of the world is sweeping every corner of the earth with more and more rapid speed, which has influenced the culture of every country. Martial arts is also faced with the reality of the internationalization of the problem, "only the nation, there is the world", martial arts can only be in the form of a national culture to carry out international cultural exchanges. In the face of the competition of the western sports, we should develop the National Traditional martial arts under the premise of keeping its own uniqueness, through the exchange and cooperation, friendly competition.

\section{Summary}

Today's society is highly competitive, but not as ancient as through this means of direct expression of war, but through political, economic, cultural, sports and other forms to reflect. Martial arts along the way, after the Ming Dynasty after this special stage, access to a new development, However, after all, different social stage, we have to popularize the martial arts fitness entertainment function, so that martial arts in the national fitness program plays an important role; The other side to improve his skill level, so that martial arts in the international sports exchanges, so that the world see the martial arts inherent martial arts function. We participate in martial arts training, on the one hand can increase our physique, self-defense skills, on the other hand we develop intelligence, cultivate national pride and patriotism.

\section{References}

[1] Jihua and so on, A Study on the Development of Chinese Martial arts Industry under the Background of Soft Power, Journal of Jilin Institute of Physical Education, vol.5, pp. 28-31, 2012

[2] Wikipedia, Chinese History / 1368 - 1644, https://cn.18dao.net/\%e4\%b8\%ad\%e5\%9b\%bd\%e5\% $8 \mathrm{e} \% 86 \%$ e5\%8f\%b2/1368\%e5\%b9\%b4-1644\%e5\%b9\%b4

[3] Tao Zhichao and so on, The Inheritance and Development of National Traditional Sports from the Perspective of School Physical Education, Wushu Science, vol.5, pp. 93-97, 2011

[4] Wang Junqi and so on, The Main Characteristics of Chinese Martial Arts and the Trend of Contemporary Development, Wushu Science, vol.6, pp. 3-5, 2004 